\title{
A Low-Cost SARS-CoV-2 rRBD ELISA to Detect Serostatus in Ecuadorian Population with COVID-19
}

\author{
Ángel Guevara, ${ }^{1 \star}$ Sandra Vivero, ${ }^{1}$ Victoria Nipaz, ${ }^{1}$ Victor Guaraca, ${ }^{2}$ and Josefina Coloma ${ }^{3}$ \\ ${ }^{1}$ Instituto de Biomedicina, Carrera de Medicina, Universidad Central, Quito, Ecuador; ${ }^{2}$ Distrito de Salud 09D13, Ministerio de Salud \\ Pública del Ecuador, Balzar, Ecuador; ${ }^{3}$ Division of Infectious Diseases and Vaccinology, School of Public Health, University of California, \\ Berkeley, Berkeley, California
}

\begin{abstract}
Laboratory diagnosis of the COVID-19 relies on RT-PCR to amplify specific fragments of SARS-CoV-2 genome. However, serological tests are required to determine the immune response elicited after infection. Here, we analyzed convalescent sera collected from positive individuals by RT-PCR to SARS-CoV-2 ( $n=78)$, Zika $(n=20)$, dengue $(n=20)$, chikungunya $(n=54)$, intestinal parasites $(n=11)$, and HIV $(n=1)$, from different areas of Ecuador, with an in-house ELISA using a SARS-CoV-2 receptor binding domain recombinant (rRBD) antigen to detect IgG antibodies elicited by SARS-CoV-2 infection. Of the 78 samples positive for SARS-CoV-2 by RT-PCR, 73 showed high absorbance value compared with the cutoff and five were negative. All tested sera from other infections showed no reactivity. Sensitivity, specificity, positive predictive value, and negative predictive value were $93.6 \%, 100 \%, 100 \%$, and $95.4 \%$, respectively. This in-house anti-lgG rRBD ELISA offers an economic and simple alternative to determine lgG immune responses after SARS-CoV-2 infection.
\end{abstract}

Because the WHO declared COVID-19 a global pandemic, ${ }^{1,2}$ more than 30 million cases and close to one million deaths have been reported worldwide, with infections most likely to be in the hundred millions. In Ecuador, the first COVID-19 case was detected on February 29, 2020, and despite containment efforts, an explosive epidemic ensued in the city of Guayaquil with alarming mortality estimates which later spread to the entire country. Strong public health measures have flattened transmission curves, but more than 127,000 confirmed cases and 11,090 deaths have been reported so far. ${ }^{3}$ In Ecuador, confirmatory laboratory diagnosis is mostly carried out through RT-PCR and loop-mediated isothermal amplification conducted by a handful of private government certified clinical and academic laboratories that offer the service at a high cost or by the public national diagnostic laboratory that offers it free of charge. In the first months of the pandemic, there was a shortage of tests, and they were used mainly for confirmation of clinical cases. Presently, asymptomatic or suspected cases can also be tested. On the other hand, serological tests to detect immunity for SARSCoV-2 are crucial to understand prevalence, to study immune responses of communities, to follow the dynamics of COVID immunity, and to support reactivation of the economy. Rapid tests with variable performance inundated the markets in Ecuador early on, each costing from $\$ 15$ to $\$ 40$, and have been used to assess individual serostatus and to conduct small seroprevalence studies. ${ }^{4}$ At this time of the pandemic, highly sensitive, low-cost, and specific serological tests to detect the presence of antibodies anti-SARSCoV-2 are required. Several viral derived proteins are used in these assays to detect specific immune responses to SARSCoV-2. Most promising is the nucleocapsid and spike glycoproteins including the receptor binding domain (RBD) of the $S$ protein. ${ }^{5,6}$ In the present study, as part of the emergency response to the public health crisis in Ecuador, an *Address correspondence to Ángel Guevara, Instituto de Biomedi-
cina, Carrera de Medicina, Universidad Central del Ecuador, Iquique
Street N14-121 and Sodiro, Quito, Ecuador, 170403. E-mail: agguevara@ uce.edu.ec unprecedented collaboration among academia, the private sector, and international partners allowed us to adapt, validate, and implement a simple and low-cost ELISA test to detect anti-SARS-CoV-2-RBD IgG in human serum. For the study, blood samples were collected by venipuncture from COVID-19 symptomatic individuals aged 18 years or older with mild and moderate symptoms, who tested positive for SARS-CoV-2 in nasopharyngeal swab samples $(n=78)$ by commercial RT-PCR tests. All individuals tested positive a minimum of 15 days before blood sampling. The samples were obtained from different geographical areas in Ecuador: Quito (highlands, $n=37$ ), Puyo (Amazon, $n=6$ ), Baños (southwest highlands, $n=13$ ), and Balzar (lowlands, $n=22$ ). To test for specificity, pre-COVID-19 sera samples $(n=49)$, obtained in 2017 from the community of Lita, northern Ecuador) stored at the Institute of Biomedicine repository of the Central University as well as convalescent sera from infected individuals with Zika $(n=20)$, dengue $(n=20)$, and chikungunya viruses $(n=54)$, one with HIV and 11 with intestinal parasitic infections, were analyzed. In five of the SARS-CoV-2 RT-PCR-positive individuals, serial samples were obtained monthly over a period of 4 months and in one up to 6 months to determine the durability of IgG anti-RBDSARS-CoV-2. Blood was collected following informed written consent under a protocol approved by the Ethics Committee of the Health Ministry of Ecuador.

The sera were tested for the presence of IgG anti-SARSCoV-2 antibodies using a recombinant RBD-SARS-CoV-2 (rRBD) antigen ELISA with modifications of previously published protocols. ${ }^{7,8}$ In brief, flat bottom 96-well ELISA plates (Nunc Maxisorp ${ }^{\mathrm{TM}}$, Thermo Fisher Scientific, Waltham, MA) were coated with $50 \mu \mathrm{L}$ of $\mathrm{rRBD}$ antigen (provided for Dr. Aubree Gordon, Michigan University and Open Philanthropy) diluted in coating buffer phosphate-buffered saline (PBS pH 7.2) and incubated overnight at room temperature. Excess antigen solution was removed, the plates were washed once with washing buffer (PBS-0.1\% Tween 20), and $100 \mu \mathrm{L}$ of blocking buffer (PBS-0.1\% Tween 20 and 4\% bovine serum albumin) was added to each well and incubated for 30 minutes at $37^{\circ} \mathrm{C}$. The plates were washed five times with washing 


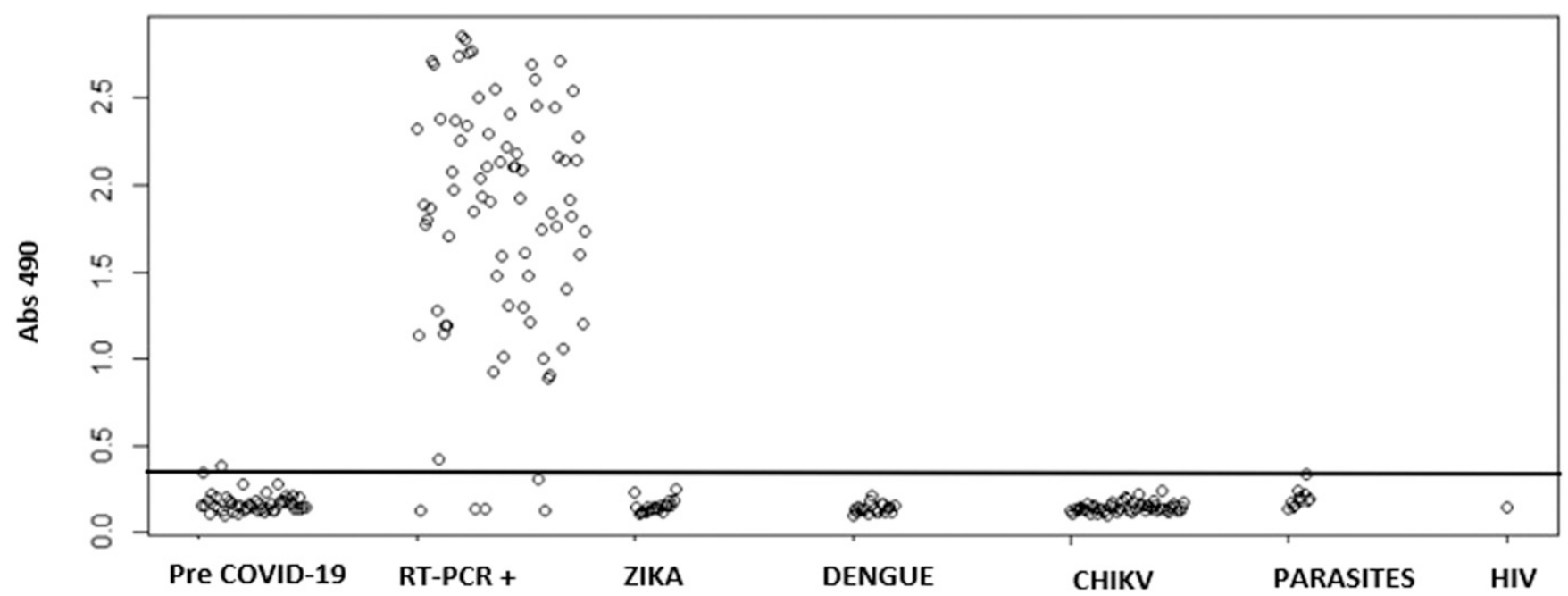

FIGURE 1. ELISA based on recombinant receptor binding domain protein IgG antibody for SARS-CoV-2 infection (pre-COVID-19, $n=49$. RT-PCR + SARS-CoV-2, $n=78$. Zika, $n=20$. Dengue, $n=20$. CHIKV, $n=54$. Intestinal parasites, $n=11$. HIV, $n=1$ ).

buffer and $100 \mu \mathrm{L}$ of unknown samples; positive and negative controls diluted 1:100 in dilution buffer (PBS-0.1\% Tween 20$5 \%$ nonfat milk) were added to the corresponding wells and incubated for 1 hour at $37^{\circ} \mathrm{C}$. The plates were washed five times with washing buffer, and $100 \mu \mathrm{L}$ of goat anti-IgG human horseradish peroxidase (Invitrogen, 31410, Rockford, IL) conjugate 1:8,000 diluted in dilution buffer were added to each well and incubated 30 minutes at $37^{\circ} \mathrm{C}$. The wells were then washed seven times with washing buffer, $100 \mu \mathrm{L}$ of ophenylenediamine dihydrochloride, and fresh substrate solution (Thermo Fisher Scientific ${ }^{\mathrm{TM}}$ ) was added, and the reaction was allowed to develop at room temperature for 10 minutes in the dark. Development was stopped by adding $100 \mu \mathrm{L}$ of $3 \mathrm{M}$ $\mathrm{HCl}$, and the absorbance of each well was read at $490 \mathrm{~nm}$ with an ELISA plate reader (Multiskan Sky. Thermo Scientific). The "cutoff" value was considered as the mean \pm 3 SDs of the absorbance values from pre-COVID-19 sera.

Using the rRBD antigen, the 49 pre-COVID-19 tested sera showed a mean absorbance plus three SDs (cutoff value) of 0.3454. Of the 78 samples positive for SARS-CoV-2 RT-PCR, $73(93.6 \%)$ showed significantly high absorbance value (mean 1.9149 , maximum value 2.8574 , and minimum value 0.4219 ) compared with the cutoff value. All of the other tested sera from other infections showed no reactivity against rRBD antigen (Figure 1). Five (6.4\%) sera from individuals positive for SARS-CoV-2 were negative (mean 0.1679 , maximum value 0.3086 , and minimum value 0.1259 ) in the present assay. This was probably due to patients not developing detectable IgG anti-RBD-SARS-CoV-2 at the time of sampling or having short-lived antibody levels. The sensitivity, specificity, positive predictive value, and negative predictive value were $93.6 \%$, $100 \%, 100 \%$, and $95.4 \%$, respectively. In relation with serial samples, five patients showed detectable levels of IgG antiRBD-SARS-CoV-2 up to 4 months post-positive SARS-CoV2 RT-PCR. In one individual, IgG levels were still detected at 6 months (Table 1).

Recent studies have shown SARS-CoV-2 RBD antigen to be very useful for accurate, sensitive, and specific detection of recent and past infection due to SARS-CoV-2. ${ }^{9}$ However, the homology of RBD-SARS-CoV-2 with other coronaviruses could cause a cross-reaction that must be considered. In conclusion, we have successfully used RBD-SARS-CoV-2based in-house ELISA to detect IgG antibodies against SARSCoV-2 as a simple, affordable, and feasible alternative test that will be extremely useful in larger seroepidemiological studies in Ecuador and elsewhere as well as to monitor the life span of IgG anti-RBD-SARS-CoV-2 in infected and/or vaccinated individuals. This study was conducted with symptomatic

TABLE 1

Serial ELISA IgG RBD-SARS-CoV-2 in samples from RT-PCR-positive people

\begin{tabular}{|c|c|c|c|c|c|}
\hline Sample & RT-PCR + & $\lg G$ RBD 1 & $\lg \mathrm{RBD} 2$ & $\operatorname{lgG}$ RBD 3 & $\operatorname{lgG}$ RBD 4 \\
\hline \multirow[t]{2}{*}{ PUYO 1} & May 28, 2020 & June 23, 2020 & July 18, 2020 & August 22, 2020 & September 19, 2020 \\
\hline & Positive & 6.4 & 5.1 & 4.6 & 4.3 \\
\hline \multirow[t]{2}{*}{ PUYO 2} & May 27, 2020 & June 23, 2020 & July 18, 2020 & August 22, 2020 & September 19, 2020 \\
\hline & Positive & 7.1 & 6.5 & 5.8 & 5.5 \\
\hline \multirow[t]{2}{*}{ PUYO 3} & May 31, 2020 & June 23, 2020 & July 18, 2020 & August 22, 2020 & September 19, 2020 \\
\hline & Positive & 3.2 & 3.1 & 2.5 & 2.2 \\
\hline \multirow[t]{2}{*}{ PUYO 4} & May 31, 2020 & June 23, 2020 & July 18, 2020 & August 22, 2020 & September 19, 2020 \\
\hline & Positive & 6.1 & 6.1 & 7.0 & 7.5 \\
\hline \multirow[t]{2}{*}{ PUYO 5} & May 31, 2020 & June 23, 2020 & July 18, 2020 & August 22, 2020 & September 19, 2020 \\
\hline & Positive & 3.9 & 3.5 & 3.5 & 3.6 \\
\hline \multirow[t]{2}{*}{ CB07 } & March 18, 2020 & April 8, 2020 & July 14, 2020 & ND & September 22,2020 \\
\hline & Positive & 6.5 & 5.3 & ND & 5.2 \\
\hline
\end{tabular}


patients. Future studies with asymptomatic populations are planned to evaluate the performance of the assay. For this study, more than 200,000 assays will be available for Ecuador at no cost.

Received November 2, 2020. Accepted for publication February 8, 2021.

Published online February 25, 2021.

Acknowledgments: We thank Ronald Guderian and Jacobus de Waard for their critical review of the manuscript. The technical advice of Magelda Montoya from UC Berkeley is also appreciated. We thank Open Philanthropy and Aubree Gordon from the University of Michigan for rRBD donation. The American Society of Tropical Medicine and Hygiene has waived the Open Access fee for this article due to the ongoing COVID-19 pandemic.

Financial support: This work received financial support from the Sustainable Sciences Institute 870 Market Street, Suite 764, San Francisco, CA 94102, and Fondo Por Todos Ecuador.

Authors' addresses: Ángel Guevara, Sandra Vivero, and Victoria Nipaz, Instituto de Biomedicina, carrera de Medicina, Universidad Central del Ecuador, Quito, Ecuador, E-mails: agguevara@uce. edu.ec,sgvivero@uce.edu.ec, and vickynipaz@gmail.com. Victor Guaraca, Distrito de Salud 09D13, Balzar, Ecuador, E-mail: mdvictorhgp@hotmail.com. Josefina Coloma, Division of Infectious Diseases and Vaccinology, School of Public Health, University of California, Berkeley, Berkeley, CA, E-mail: colomaj@berkeley.edu.

This is an open-access article distributed under the terms of the Creative Commons Attribution (CC-BY) License, which permits unrestricted use, distribution, and reproduction in any medium, provided the original author and source are credited.

\section{REFERENCES}

1. Wenjie $T$ et al., 2020. A novel coronavirus genome identified in a cluster of pneumonia cases-Wuhan, China 2019-2020. China CDC Weekly 2: 61-62.

2. Available at: https://www.who.int/dg/speeches/detail/who-directorgeneral-s-opening-remarks-at-the-media-briefing-on-covid-19--11-march-2020. Accessed August 23, 2020.

3. Available at: https://coronavirus.jhu.edu/map.html. Accessed September 20, 2020.

4. Available at: https://www.salud.gob.ec/msp-aplico-pruebas-rapidaspara-covid-19-en-la-parroquia-febres-cordero/. Accessed February 12, 2021.

5. Ju B et al., 2020. Human neutralizing antibodies elicited by SARSCoV-2 infection. Nature 584: 115-119.

6. Kai-Wang To K et al., 2020. Temporal profiles of viral load in posterior oropharyngeal saliva samples and serum antibody responses during infection by SARS-CoV-2: an observational cohort study. Lancet Infect Dis 20: 565-574.

7. Stadlbauer D et al., 2020. SARS-CoV-2 seroconversion in humans: a detailed protocol for a serological assay, antigen production, and test setup. Curr Protoc Microbiol 57: e100.

8. Amanat $F$ et al., 2020. A serological assay to detect SARS-CoV-2 seroconversion in humans. Nat Med 26: 1033-1036.

9. Iyer $A$ et al., 2020. Persistence and decay of human antibody responses to the receptor binding domain of SARS-CoV-2 spike protein in COVID-19 patients. Sci Immunol 5: eabe0367. 